\title{
Quality of life, self-stigma, and hope in schizophrenia spectrum disorders: a cross-sectional study
}

\author{
This article was published in the following Dove Press journal: \\ Neuropsychiatric Disease and Treatment \\ 23 February 2017 \\ Number of times this article has been viewed
}

\section{Kristyna Vrbova' \\ Jan Prasko' \\ Marie Ociskova' \\ Dana Kamaradova' \\ Marketa Marackova' \\ Michaela Holubova ${ }^{1,2}$ \\ Ales Grambal' \\ Milos Slepecky ${ }^{3}$ \\ Klara Latalova'}

'Department of Psychiatry, Faculty of Medicine and Dentistry, University Palacky Olomouc, University Hospital Olomouc, Olomouc, ${ }^{2}$ Department of Psychiatry, Hospital Liberec, Liberec, Czech Republic; ${ }^{3}$ Department of Psychology Sciences, Faculty of Social Science and Health Care, Constantine the Philosopher University in Nitra, Nitra, Slovakia
Correspondence: Kristyna Vrbova Department of Psychiatry, Faculty of Medicine and Dentistry, University Palacky Olomouc, University Hospital Olomouc, I.P.Pavlova 6, 775 20,

Olomouc, Czech Republic Email krist@atlas.cz
Goals: The aim of this study was to explore the quality of life, self-stigma, personality traits, and hope in patients with schizophrenia spectrum disorders.

Patients and methods: A total of 52 outpatients participated in this cross-sectional study. The attending psychiatrist assessed each patient with Mini International Neuropsychiatric Interview (MINI). The patients then completed Quality of Life Satisfaction and Enjoyment Questionnaire (Q-LES-Q), Internalized Stigma of Mental Illness (ISMI) Scale, Temperament and Character Inventory - Revised (TCI-R), Adult Dispositional Hope Scale (ADHS), Drug Attitude Inventory 10 (DAI-10), and Liebowitz Social Anxiety Scale (LSAS)-Self-report. The psychiatrist evaluated Clinical Global Impression Severity - the objective version (objCGI-S), and the patients completed the Clinical Global Impression Severity - the subjective version (subjCGI-S). Each participant also completed Beck Depression Inventory-II (BDI-II), and Beck Anxiety Inventory (BAI).

Results: The quality of life was significantly higher in employed patients and individuals with higher hope, self-directedness (SD), and persistence (PS). The quality of life was lower among patients with higher number of psychiatric hospitalizations, those with higher severity of the disorder, and individuals who were taking higher doses of antipsychotics. Patients with more pronounced symptoms of depression, anxiety, and social anxiety had a lower quality of life. Finally, the quality of life was lower among individuals with higher harm avoidance (HA) and self-stigmatization (ISMI). Backward stepwise regression was applied to identify the most significant factors connected to self-stigma. The regression analysis showed that occupation, level of depression (BDI-II), attitude to using medication (DAI-10), social anxiety (LSAS), and antipsychotic index were the most relevant factors associated with lower quality of life.

Conclusion: Detection of the quality of life in the context of personality traits, hope, selfstigma, and demographic and clinical factors may be an important part of the assessment of the patient with schizophrenia.

Keywords: quality of life, schizophrenia, personality traits, self-stigma, hope, depression, anxiety

\section{Introduction}

Recently, as a product of an increased emphasis on patients' experiences and their needs, the awareness on the quality of life has been taken into account in the exploration of psychiatric conditions, such as schizophrenia. ${ }^{1}$ The dimension of the quality of life offers additional information that benefits a multidimensional view in research and treatment of severe mental disorders. ${ }^{2-9}$ Research data have found that the quality of life is significantly reduced in schizophrenia. ${ }^{10-12}$ There are many factors that could negatively influence the quality of life in psychiatric patients, such as age, the severity of 
psychopathology, the number of psychiatric hospitalizations, the comorbidity with depression, social anxiety, avoidance, poor or no partnership, low education, unemployment, and low self-esteem. ${ }^{1,9,12-16}$

In the last few years, the focus of attention has moved to the more gentle factors influencing the quality of life. According to Snyder, hope is related to the life goals and expectations of a positive outcome of the own effort. ${ }^{17,18}$ His concept of hope includes emotion, motivation, behavior, and cognition. ${ }^{19}$ The basic level of hope remains relatively stable over time, which makes it resemble a personality trait. ${ }^{18}$ In patients with schizophrenia, the relationships among hope, depression, and self-stigma are interconnected. ${ }^{20}$

In individuals suffering from a schizophrenic disorder, it was also found that internalized stigma moderates the connections among insight, social functioning, hope, and self-efficacy. ${ }^{21}$ These factors have been linked to the quality of life.

The robust factor that influences the quality of life is selfstigma. ${ }^{11,16,22,23}$ Self-stigma is a three-phase process in which the person assigns to himself/herself a socially handicapping label, internalizing it, and assumes that others will behave in a negative way to him/her, or despise him/her. ${ }^{24-26}$ Higher rates of self-stigma are connected to a higher rate of overall psychopathology, a higher rate of depression, social anxiety, low self-esteem, a lesser degree of hope, worse social, occupational and vocational functioning, poorer treatment outcomes, less social support and less cooperation in the treatment, and last but not least a lower quality of life. ${ }^{24,27-34}$ This may lead to avoidance, running away from friends, sometimes even from their families, and ultimately to social isolation. ${ }^{13}$ The prevalence of self-stigmatizing attitudes in persons with a severe mental illness varies between $36 \%$ and $42 \%$ in recent European studies. ${ }^{35,36}$

Stereotypes and prejudices about the psychiatric patients typically appraise the mentally ill as dangerous, aggressive, irrational in negotiations, and therefore unpredictable and irresponsible. ${ }^{37,38}$ Formerly, the stigma and risks of stigma internalization were reported particularly in patients with severe mental disorders such as schizophrenia, ${ }^{24,34}$ bipolar disorder, ${ }^{39}$ and major depressive disorder. ${ }^{40,41}$

As for the self-stigma among patients with severe mental illness, several findings have shown that it presents an important topic in this population. ${ }^{16,22}$ The results of a systematic review of Gerlinger et a ${ }^{15}$ suggest that from one-third to one-half of the patients with schizophrenia feel shame as a consequence of the disorder. However, not every person with a mental disorder who perceived stereotypes from the others internalized the stigma. ${ }^{42}$ Therefore, it may be useful to identify which personality traits could be related to selfstigma importantly.

For the identification of personality variables that may play a role in determining the internalized stigma, Cloninger's biosocial theory of personality can be used. ${ }^{43,44}$ It has been found that self-stigma of the persons with a mental disorder is accompanied with higher harm avoidance (HA) and lower self-directedness (SD) and persistence (PS). ${ }^{28} \mathrm{SD}$ and PS are also fundamental parts of Snyder's cognitive theory of hope. ${ }^{17}$

The present study is part of a bigger project of the Psychiatric Department of University Hospital and Faculty of Medicine and Dentistry, Palacky University Olomouc, which concentrated on mapping the self-stigma of psychiatric patients with different diagnoses (schizophrenia, bipolar affective disorder, anxiety disorders, depression, and borderline personality disorder) and exploring the connection of self-stigma with psychopathology, diagnosis, demographic factors, quality of life, disability, and several personality traits. We separately mapped the situation in patients who were hospitalized and patients in outpatient facilities. The members of our team are responsible for the different diagnoses and settings and the published results of the topic. We published several articles based on the results of this project. ${ }^{11,12,19,23,34,39}$ The next step will be the development of psychoeducational and Internet programs focused on decreasing the self-stigma.

The aim of the current study was to examine to what extent the demographic factors, the severity of the disorder, hope, self-stigma, and personality traits have affected the quality of life in stabilized patients with schizophrenia spectrum disorders. The main hypotheses of the study, derived from the abovementioned knowledge, were as follows: 1) the severity of the disorder is negatively correlated with the quality of life, 2) patients, who have higher hope, also have higher quality of life, 3) quality of life is negatively linked to the self-stigma, and 4) quality of life is negatively associated with HA and positively with SD.

\section{Patients and methods}

\section{Patients}

Fifty-two patients of both sexes attending an outpatient psychiatric clinic in stable condition (the patients without need of hospitalization, changes in medication, or other therapeutic intervention) participated in this study. The structured interview, Mini International Neuropsychiatric 
Interview (MINI), was used to confirm the diagnosis. ${ }^{45}$ Inclusion criteria were:

(1) Age 18-65 years.

(2) Diagnosis of schizophrenia spectrum disorders according to 10th revision of the International Statistical Classification of Diseases (ICD-10) and Diagnostic and Statistical Manual of Mental Disorders, Fifth Edition $(D S M-5){ }^{46,47}$

(3) The severity of the illness was determined through interview with the doctor, who evaluated the severity on the Clinical Global Impression Severity - the objective version (objCGI-S) scale. ${ }^{48}$

Exclusion criteria were:

(1) Presence of a severe physical illness.

(2) Intellectual disability or organic mental disorder.

\section{Assessment instruments}

All patients completed assessment scales, and questionnaires. The methods were assessed in two sessions during 2 weeks. In the first session, the instruments MINI, Liebowitz Social Anxiety Scale (LSAS)-Self-report, Beck Anxiety Inventory (BAI), Beck Depression Inventory-II (BDI-II), CGI, Adult Dispositional Hope Scale (ADHS), and DAI-10 were used. Other questionnaires were allocated in the following session. The reasons were the attention disabilities of the patients with schizophrenia. The following assessment tools were used:

- MINI - MINI is a structured interview covering diagnostic criteria for common psychiatric disorders according to the Diagnostic and Statistical Manual of Mental Disorders, Fourth Edition (DSM-IV), and ICD$10 .{ }^{45}$ Interrater reliability is 0.75 or higher in all portions of the diagnostic assessment, except the less reliable current manic episode.

- The Quality of Life Satisfaction and Enjoyment (Q-LES-Q) - the questionnaire with 93 items is divided into eight domains to assess. The patients evaluate each domain by choosing one number from a five-point Likert scale according to their level of satisfaction in the specific domain. ${ }^{1}$ The completion takes 20-30 minutes. Patients fulfill the domains of "Physical health, Feelings, Leisure, Household, Work, School/study, Social Relations, General, and a Sum of the quality of life". Müllerova ${ }^{49}$ validated the Czech version of the Q-LES-Q.

- LSAS - the scale consists of 24 items related to different social situations. ${ }^{50}$ The patients are asked to evaluate the level of anxiety (LSAS) and degree of avoidant behavior in each situation. The LSAS is a regularly used clinician-administered instrument. The present study used its self-report version. Fresco et al ${ }^{51}$ tested the psychometric properties of the LSAS-self-report in contrast to the LSAS-clinician administered. There was a minimal difference between the two versions of the LSAS on any scale or subscale score. Both versions were internally consistent, and the subscale intercorrelations for both forms were principally equal. Baker et $\mathrm{al}^{52}$ reported on the properties of the LSAS-self-report. The questionnaire exhibited excellent psychometric properties as shown by the outcomes of test-retest reliability, internal consistency, and convergent and discriminant validity. Moreover, the measure was sensitive to treatment change.

- The Internalized Stigma of Mental Illness (ISMI) Scale - the scale consists of 29 items with a four-point scale, which evaluates five areas of self-stigma. ${ }^{53}$ These include feelings of alienation that the person is not a full member of society, the rate of stereotypes endorsement about people with mental illness, perceived discrimination (how the patient feels the behavior from others to him from the time of diagnosis), social withdrawal, and the degree of stigma resistance. ${ }^{53,54}$ ISMI was standardized by Ocisková et $\mathrm{al}^{55}$ in the Czech Republic. Internal consistency of the Czech version of the scale was excellent (Cronbach's alpha $=0.91)$.

- BAI-BAI consists of 21 items with a four-point Likert scale, according to which an individual indicates the severity of anxiety symptoms, suffered in the previous week. ${ }^{56}$ Kamaradova et al ${ }^{57}$ validated BAI in Czech. The inventory exhibited excellent internal consistency (Cronbach's alpha $=0.92$ ).

- BDI-II-BDI includes 21 items of which the patients select one of the four defined options that best matches how they have felt in the last 2 weeks. ${ }^{58}$ Correlation of BDI-II with other standardized scales of depression is $\sim 0.70$, internal consistency (Cronbach's alpha) ranges from 0.73 to $0.95 .{ }^{59}$ The test was adapted to Czech population. ${ }^{60}$

- Clinical Global Impression (CGI) - the CGI is an assessment of overall severity of the disorder. ${ }^{48}$ The source of the evaluation in objCGI-S is an overall assessment of the patient by a physician. In its subjective version (subjCGI-S), the patient evaluates the overall condition. The range of the scale is from 1 (normal, with no signs of illness) to 7 (extremely severe symptoms of the disease).

- Temperament and Character Inventory-Revised(TCI-R)the questionnaire involves 240 items, of which five are for validation. ${ }^{44}$ The questionnaire evaluates the four temperament and three character traits of the personality. 
The features of temperament include novelty seeking (NS), HA, reward dependence (RD), and PS. The character traits are SD, cooperativeness (CO), and Selftranscendence (ST) ${ }^{61}$ Preiss and Klose ${ }^{62}$ created Czech percentile norms.

- ADHS - the scale consists of the 12 items - four assess the ability to set the adaptive path to the goal, four focus on effort, and four are distractors. ${ }^{17}$ The patient selects the degree of agreement with the statement on an eight-point scale. Ocisková et $\mathrm{al}^{19}$ standardized the scale to Czech. The translation had a good degree of internal consistencythe overall Cronbach's alpha was 0.85 .

- Drug Attitude Inventory (DAI-10) - DAI-10 is a questionnaire made to measure patients' attitudes toward medications. ${ }^{63}$ The patient decides whether statements about drugs are true or false. The statements are concerned with drug effectiveness, necessity, and adherence. The instrument assesses the current attitudes toward medications, not whether the patients discontinued their medication in the past.

- Demographic questionnaire contained the basic information - sex, age, marital status, education, employment, disability, age of the disorder onset, duration of outpatient psychiatric treatment, the number of hospitalizations, length of last hospitalization, number of visited psychiatrists, medications, and data on stopping medication in the past (on the recommendation of a psychiatrist or willingly).

\section{Statistics}

The statistical programs Prism (GraphPad PRISM version 5.0; GraphPad Software Inc., La Jolla, CA, USA) and SPSS 24.0 (IBM Corp., Armonk, NY, USA) were used for the statistical estimation of the results. Demographic data and the average scores in the distinct questionnaires and scales were evaluated using descriptive statistics (mean, median, standard deviation, and the character of data distribution). Mean values were compared by using unpaired $t$-tests. Relationships between categories were calculated using correlation coefficients. Fisher's exact test was used to verify the relationship between alternative variables (sex, marital status, and discontinuation of medication). Backward stepwise regression was used to test the importance of each significant correlation coefficient. All statistical tests were considered acceptable at $5 \%$ level of statistical significance.

\section{Ethics}

The local ethical committee of University Palacky Olomouc, Faculty of Medicine and Dentistry, approved the study. The research was conducted according to the latest version of the Declaration of Helsinki and recommendations for good clinical praxis. ${ }^{64,65}$ All patients signed written informed consent for this study.

\section{Medication management}

All patients were treated at a psychiatric clinic and were currently in a stable mental condition. All patients had been prescribed antipsychotics in the range of advised therapeutic doses (mean 5.59 $\pm 3.84 \mathrm{mg}$ dose of the antipsychotics index; converted to the dosage on the dosage of risperidone). In addition to the antipsychotic medication, 21 patients (40.4\%) were also treated with antidepressants, five patients $(9.6 \%)$ by benzodiazepine anxiolytics, and five patients $(9.6 \%)$ by mood stabilizers. Drugs were administered according to the recommended Czech guidelines for the treatment of schizophrenia. ${ }^{66}$

\section{Results \\ Description of the sample}

The data were collected during the period from May 2015 to August 2016. Fifty patients (96.2\%) completed the questionnaires. The demographic, clinical, and measured data are described in Table 1.

The primary diagnosis was schizophrenia spectrum disorder in all 52 patients ( 27 were diagnosed with schizophrenia, three with delusional disorder, 11 with acute and transient psychotic disorders, and 11 with schizoaffective disorder). Five patients had comorbid substance abuse disorder, and two patients suffered from a comorbid personality disorder.

Quality of Life Enjoyment and Satisfaction Questionnaire (Q-LES-Q)-total score (SUM) reached 271.24 \pm 59.57 points. Regarding the severity of the illness, the psychiatrist assessed the current state in average between "borderline" to "mild symptoms of the disease." The mean of the subjective assessment of illness severity by patients (subjCGI-S) differs significantly from an objective evaluation (Mann-Whitney test, $U=888 ; P<0.05$ ) and the subjective and objective assessment of disease severity together are significantly correlated (Spearman $r=0.59, P<0.001$ ).

Patients reached in average the mild symptoms of depression. ${ }^{60}$ Their average total score of anxiety was also mild (Table 1). ${ }^{57}$ The results of the questionnaire TCI-R, which evaluate the personality traits, are shown in Table 1. Compare to Czech standards, the sample showed the average level of RD (40-45 percentile), SD (40-45 percentile), cooperation (55 percentile), and ST (55 percentile). The degree HA was significantly higher than that given norm ( $80-85$ percentile). The average rate of NS and PS was considerably lower in comparison with norms (NS was located at 35-40 percentile and PS was at the level of 30-35 percentile). Regarding 
Table I Sample description: demographic, clinical, and measured data

\begin{tabular}{|c|c|}
\hline Category & $\begin{array}{l}\text { Figures or } \\
\text { mean values }\end{array}$ \\
\hline Number of patients & 52 \\
\hline Age & $35.94 \pm 9.50$ \\
\hline Sex: men/women & $27 / 25$ \\
\hline $\begin{array}{l}\text { Education: basic/vocational training/secondary/ } \\
\text { university }\end{array}$ & $8 / 19 / 16 / 9$ \\
\hline Occupation: yes/no/unknown & $26 / 25 / 1$ \\
\hline Pension: no/full/partial & $26 / 18 / 8$ \\
\hline Marital status: single/married/divorced/widowed & $36 / 9 / 5 / 2$ \\
\hline Partner: yes/no & $15 / 37$ \\
\hline Onset of the disorder: years & $29.24 \pm 9.48$ \\
\hline Number of hospitalizations & $3.36 \pm 3.01$ \\
\hline Length of the treatment & $7.04 \pm 8.17$ \\
\hline Positive family history: no/yes & $29 / 23$ \\
\hline objCGI-S & $2.74 \pm 0.99$ \\
\hline subjCGI-S & $2.30 \pm 1.43$ \\
\hline BDI-II & $15.04 \pm 10.30$ \\
\hline BAI & $12.31 \pm 9.88$ \\
\hline LSAS-total & $90.70 \pm 25.08$ \\
\hline Fear & $44.17 \pm 12.72$ \\
\hline Avoidance & $46.60 \pm 13.28$ \\
\hline ADHS-total & $39.76 \pm 11.02$ \\
\hline Pathway & $19.61 \pm 5.50$ \\
\hline Agency & $20.14 \pm 6.98$ \\
\hline DAI-10 & $3.96+3.69$ \\
\hline ISMI-total & $60.44 \pm 13.73$ \\
\hline Alienation & $12.66 \pm 4.07$ \\
\hline Stereotypes endorsement & $13.14 \pm 3.63$ \\
\hline Perceived discrimination & $9.88 \pm 3.22$ \\
\hline Social withdrawal & $12.32 \pm 3.55$ \\
\hline Stigma resistance & $12.52 \pm 2.35$ \\
\hline Novelty seeking & $96.12 \pm 10.80$ \\
\hline Harm avoidance & $110.62 \pm 19.44$ \\
\hline Reward dependence & $94.40 \pm 10.00$ \\
\hline Persistence & $104.58 \pm 18.08$ \\
\hline Self-directedness & $134.22 \pm 16.65$ \\
\hline Cooperativeness & $126.32 \pm 12.69$ \\
\hline Self-transcendence & $71.08 \pm 15.85$ \\
\hline Q-LES-Q-SUM & $271.24 \pm 58.57$ \\
\hline Q-LES-Q (\%) & $58.00 \pm 13.00$ \\
\hline Physical health & $41.78 \pm I I .26$ \\
\hline Feelings & $45.90 \pm 11.93$ \\
\hline Work & $29.74 \pm 20.21$ \\
\hline Household & $33.44 \pm 13.66$ \\
\hline School & $13.94 \pm 10.16$ \\
\hline Leisure activities & $20.82 \pm 5.34$ \\
\hline Social relations & $35.92 \pm 9.48$ \\
\hline General & $49.70 \pm 12.23$ \\
\hline $\begin{array}{l}\text { Antipsychotic index (calculated to risperidone } \\
\text { daily dose) }(n=49)\end{array}$ & $5.55 \pm 3.81$ \\
\hline $\begin{array}{l}\text { Antidepressant index (calculated to paroxetine } \\
\text { daily dose) }(n=23)\end{array}$ & $27.83 \pm 12.23$ \\
\hline $\begin{array}{l}\text { Anxiolytic index (calculated to diazepam daily } \\
\text { dose) }(n=7)\end{array}$ & $9.29 \pm 4.50$ \\
\hline
\end{tabular}

Abbreviations: ADHS, Adult Dispositional Hope Scale; BAI, Beck Anxiety Inventory; BDI-II, Beck Depression Inventory-II; DAI- 10, Drug Attitude Inventory 10; ISMI, Internalized Stigma of Mental Illness; LSAS, Liebowitz Social Anxiety Scale; objCGI-S, Clinical Global Impression Severity - the objective version; Q-LES-Q, Quality of Life Satisfaction and Enjoyment Questionnaire; Q-LES-Q-SUM, Quality of Life Satisfaction and Enjoyment Questionnaire total score; subjCGI-S, Clinical Global Impression Severity - the subjective version.
ADHS, group average score corresponds to the third sten of standards, which means a very low rate of hope..$^{15}$

\section{Quality of life and demographic factors}

Age and the age of onset of the disease did not significantly correlate with the Q-LES-Q-SUM, but there was a statistically significant correlation between Q-LES-Q-SUM and both the number of hospitalizations and the length of the treatment in years (Table 2).

There was no significant difference in the average Q-LESQ-SUM between men and women (men 262.9 \pm 57.68 versus women 280.10 \pm 60.66 ; unpaired $t$-test: $t=1.015$, $d f=47$; ns), between patients with and without a partner (with a part-

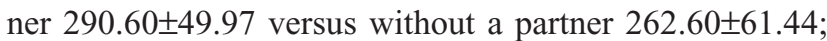

Table 2 Correlation coefficients and statistical significance between Q-LES-Q-SUM and demographic, clinical, and psychological factors

\begin{tabular}{|c|c|}
\hline Finding & Correlation coefficient \\
\hline Age & $-0.14^{\mathrm{P}}$ \\
\hline Onset of the disorder & $0.24^{\mathrm{P}}$ \\
\hline Number of hospitalizations & $-0.48^{\mathrm{S}, *}$ \\
\hline Length of the treatment & $-0.43^{\mathrm{P}, *}$ \\
\hline objCGI-S & $-0.48^{\mathrm{s}, *}$ \\
\hline subjCGI-S & $-\left.0.5\right|^{5, *}$ \\
\hline BDI-II & $-0.63^{\mathrm{P}, *}$ \\
\hline BAI & $-0.4 I^{\mathrm{P}, *}$ \\
\hline LSAS-total & $-0.70^{P, *}$ \\
\hline Fear & $-0.69^{\mathrm{P}, * *}$ \\
\hline Avoidance & $-0.66^{\mathrm{P}, *}$ \\
\hline ADHS-total & $0.5 I^{\mathrm{P}, *}$ \\
\hline Pathway & $0.43^{\mathrm{P}, *}$ \\
\hline Agency & $0.47^{\mathrm{P}, *}$ \\
\hline DAI-10 & $0.3 I^{\mathrm{P}, * * *}$ \\
\hline ISMI-total & $-0.63^{\mathrm{P}, *}$ \\
\hline Alienation & $-0.60^{\mathrm{P}, * * *}$ \\
\hline Stereotypes endorsement & $-0.53^{\mathrm{P}, *}$ \\
\hline Perceived discrimination & $-0.50^{\mathrm{P}, *}$ \\
\hline Social withdrawal & $-0.60^{\mathrm{P}, *}$ \\
\hline Stigma resistance & $0.19^{\mathrm{P}}$ \\
\hline Novelty seeking & $-0.13^{P}$ \\
\hline Harm avoidance & $-0.57^{\mathrm{P}, *}$ \\
\hline Reward dependence & $-0.10^{p}$ \\
\hline Persistence & $0.39^{\mathrm{P}, * *}$ \\
\hline Self-directedness & $0.60^{\mathrm{P}, *}$ \\
\hline Cooperativeness & $0.20^{\mathrm{P}}$ \\
\hline Self-transcendence & $-0.10^{\mathrm{P}}$ \\
\hline Antipsychotic index $(n=49)$ & $-0.46^{\mathrm{s}, *}$ \\
\hline Antidepressant index $(n=23)$ & $-0.18^{p}$ \\
\hline Anxiolytic index $(n=7)$ & $-0.35^{P}$ \\
\hline
\end{tabular}

Notes: Bold values represent as $\mathrm{P}$, Pearson $r$; S, Spearman $r$. $* P<0.001$. $* * P<0.01$. $* * * p<0.05$.

Abbreviations: ADHS, Adult Dispositional Hope Scale; BAI, Beck Anxiety Inventory; BDI-II, Beck Depression Inventory-II; DAI- 10, Drug Attitude Inventory 10; ISMI, Internalized Stigma of Mental Illness; LSAS, Liebowitz Social Anxiety Scale; objCGI-S, Clinical Global Impression Severity - the objective version; Q-LES-Q, Quality of Life Satisfaction and Enjoyment Questionnaire; Q-LES-Q-SUM, Quality of Life Satisfaction and Enjoyment Questionnaire total score; subjCGI-S, Clinical Global Impression Severity - the subjective version. 
unpaired $t$-test: $t=1.457, d f=47$; ns), but there was a significant difference in the mean Q-LES-Q-SUM between the employed and unemployed patients (with a job 300.90 \pm 49.94 versus without a job 244.20 \pm 55.83 ; unpaired $t$-test: $t=3.692, d f=46$; $P<0.001)$.

\section{Quality of life, the severity of the disorder, level of depression, and anxiety}

Q-LES-Q-SUM negatively correlated with the overall severity of the disorder, as evaluated by a doctor (objCGI-S) and the patients themselves (subjCGI-S; Table 2). The rate of the Q-LES-Q-SUM also negatively correlated with the severity of anxiety symptoms evaluated by BAI, the severity of depressive symptoms assessed by BDI-II, and severity of social anxiety symptoms assessed by LSAS (Table 2).

\section{Quality of life and hope}

Q-LES-Q-SUM positively correlated with the experienced hope evaluated by ADHS (Table 2). Patients with a higher quality of life experienced higher levels of hope, as assessed by the total score of ADHS, so by both its subscales Agency and Pathways (Table 2).

\section{Q-LES-Q-SUM and adherence}

We also evaluated the correlation between quality of life and adherence to treatment measured by DAI-10. We found that Q-LES-Q-SUM positively correlated with the current adherence to the treatment (Table 2).

\section{Q-LES-Q-SUM and self-stigma}

Q-LES-Q-SUM significantly negatively correlated with selfstigma assessed by ISMI-total and all ISMI domains except Stigma resistance (Table 2).

\section{Q-LES-Q-SUM and personality traits}

Q-LES-Q-SUM significantly negatively correlated with personality temperamental trait HA and positively with character traits PS and SD (Table 2).

\section{Q-LES-Q-SUM and medication}

Q-LES-Q-SUM significantly negatively correlated with the daily dosages of antipsychotic adjusted to the risperidone dosage (the antipsychotic index) and not with the dosages of antidepressants or anxiolytics.

\section{Regression analysis}

Because various factors significantly correlated with the Q-LES-Q-SUM, a multiple regression analysis was conducted
Table 3 Multiple regression analysis of Q-LES-Q-SUM as dependent variable with demographic and clinical factors as predictors

\begin{tabular}{llllll}
\hline Regressors & B & SE & $\boldsymbol{\beta}$ & $\boldsymbol{t}$ & Significance \\
\hline Occupation & 22.973 & 10.202 & 0.192 & 2.252 & 0.030 \\
BDI-II & -2.146 & 0.448 & -0.374 & -4.795 & 0.000 \\
LSAS-total score & -0.900 & 0.211 & -0.370 & -4.272 & 0.000 \\
DAI-10 & 3.939 & 1.201 & 0.247 & 3.279 & 0.002 \\
Antipsychotic index & -4.190 & 1.287 & -0.257 & -3.255 & 0.002 \\
\hline
\end{tabular}

Notes: ANOVA: $F=31.35, d f=46 ; P<0.001$, adjusted $r^{2}=0.767$.

Abbreviations: ANOVA, analysis of variance; BDI-II, Beck Depression InventoryII; DAI-10, Drug Attitude Inventory 10; LSAS, Liebowitz Social Anxiety Scale; Q-LES-Q, Quality of Life Satisfaction and Enjoyment Questionnaire; Q-LES-Q-SUM, Quality of Life Satisfaction and Enjoyment Questionnaire total score; SE, standard error; $B$, unstandardized coefficients $B ; \beta$, standardized coefficients $\beta$; $t$, statistic.

to detect the most central factors associated with the quality of life in persons with schizophrenia. The dependent variable was the Q-LES-Q-SUM. Independent variables were the number of hospitalizations, occupation, objCGI-S, BDI-II, LSAS-total, DAI-10, ADHS-total, antipsychotic index, and personality traits HA, PS, and SD. Because of the presence of many predictors that could reduce the chance of false positives, we separated the demographic and clinical predictors versus personality predictors into separate regressions.

During the four steps of the backward stepwise regression using demographic and clinical factors as predictors, occupation, BDI-II, LSAS-total score, DAI-10, and antipsychotic index passed with statistical significance (Table 3).

During the six steps of the backward stepwise regression using personality factors as predictors, harm-avoidance and SD passed with statistical significance (Table 4).

\section{Discussion}

The main aim of this research was to investigate the factors that may be significantly associated with the quality of life in patients with schizophrenia spectrum disorders. Most research on the topic of quality of life showed a significant link between low quality of life and greater intensity of symptoms of depression, anxiety, and overall severity of the disorder. ${ }^{9,11}$ The interesting result of the study was that

Table 4 Multiple regression analysis of Q-LES-Q-Sum as dependent variable with personality factors as predictors

\begin{tabular}{llllll}
\hline Regressors & $\boldsymbol{B}$ & SE & $\boldsymbol{\beta}$ & $\boldsymbol{t}$ & Significance \\
\hline HA & -0.996 & 0.412 & -0.331 & -2.415 & 0.020 \\
SD & $\mathrm{I} .421$ & $0.48 \mathrm{I}$ & 0.404 & 2.952 & 0.005 \\
\hline
\end{tabular}

Notes: ANOVA: $F=17.85, d f=49 ; P<0.001$, adjusted $r^{2}=0.407$.

Abbreviations: ANOVA, analysis of variance; HA, harm avoidance; Q-LES-Q, Quality of Life Satisfaction and Enjoyment Questionnaire; Q-LES-Q-SUM, Quality of Life Satisfaction and Enjoyment Questionnaire total score; SD, self-directedness; $\mathrm{SE}$, standard error; $B$, unstandardized coefficients $B ; \beta$, standardized coefficients $\beta$; $t, t$ statistic. 
the mean of the subjective assessment of illness severity by patients differs significantly from an objective evaluation assessed by the psychiatrist. It can reflect the poor insight that has frequently been detected in schizophrenia patients.

Our study confirmed the previous results., ${ }^{911}$ The quality of life correlated negatively with objective or subjective evaluation of the severity of the disorder, also with the level of depression and/or anxiety. It is a question whether the severity of the disorder is such an important factor, which can overcome all other factors, such as personality traits, hope, and self-stigma, which are considered to be more durable longitudinal factors. Nevertheless, backward regression analysis showed that although the severity of the disorder was an important factor, other factors were more significant in their relation to the quality of life.

The second aim of the presented investigation was to search for the relationship between quality of life and hope. Both the rates of ADHS total score and individual subscore of Pathways thinking (goal planning) and Agency (goal motivation) significantly positively correlated with the quality of life. Patient with higher hope has a higher quality of life and vice versa. Hope is not ignorance; it is to some extent about character traits. Hope is some level of spirituality, but sometimes it can be eroded through life experiences (ie, numbers of psychiatric hospitalizations). The cross-sectional study cannot answer the question what is first - the hope or the quality of life.

The third aim of the survey was the exploration of the relationship between the quality of life and self-stigma. The mean total score of ISMI reaches the similar values, as in our previous study in the same diagnostic population ${ }^{23}$ and also in other populations of outpatients with schizophrenia in the Czech Republic. ${ }^{12}$ The score of Q-LES-Q was also high in patients with bipolar disorder. ${ }^{39}$ Patients with schizophrenia spectrum disorders have a medium degree of self-stigma, very close to the average degree of the ISMI in the Czech patient population. ${ }^{55}$

The outcomes indicate that the level of the self-stigma was significantly negatively correlated with the quality of life. In the Czech patients with schizophrenia, the same results were shown in the cross-sectional study by Holubova et al. ${ }^{11,12}$ The question is if the decreased quality of life is one of the consequences of self-stigma or the high level of the self-stigma is a result of the poor quality of life. Prospective longitudinal investigations are desirable for answering this question.

The fourth aim of our study was to examine how the personality traits may influence the quality of life in schizophrenia spectrum disorders patients. The negative relationship between the quality of life and anxiety was also partially confirmed by a significant correlation between the quality of life and HA in the TCI-R. HA indicates the presence of anticipatory anxiety, fear of uncertainty, shyness, and fatigability ${ }^{67}$ Individuals with high levels of HA are also sensitive to criticism and rejection by others and require more frequent expressions of support and reassurance that their actions are adequate. ${ }^{68}$ It would be interesting to examine whether brashness or lack of social tact claims lead to an improved quality of life.

Furthermore, it was also found that the quality of life is significantly higher in individuals with higher SD. This may mean that patients with improved quality of life devote more effort to achieve their goals and and also have higher self-esteem. It is also likely that patients with higher levels of SD are less criticized and have internalized more positive attitudes about themselves. On the other side, that may be true only partially. High SD can be associated with subsequent ambitions, disappointments, and loss of hope. Logically, the level of PS positively corresponds with the quality of life. But only HA and SD passed with statistical significance in regression analysis using personality factors as a predictors.

HA correlated with the quality of life. This is in line with Cloninger ${ }^{67}$ who postulated HA as a feature of temperament that is largely hereditary and is not subject to significant changes in later life. SD is a character trait which has been developed throughout life experiences. ${ }^{67} \mathrm{HA}$ is a trait associated with increased susceptibility to aversive stimuli and the subsequent tendency to avoidant behavior. ${ }^{67}$ It seems, therefore, that this trait can meaningfully predict the occurrence of the poor quality of life in patients with the schizophrenic disorder. Cloninger ${ }^{43}$ believes that SD changes during the life. It is probable that poor quality of life may also lead to a reduction of SD. However, the significance of the regression analysis is limited due to an insufficient number of subjects.

\section{Limitations of the study}

The present study has several limitations. In particular, it is not possible to explain causality of the described relations. The research sample of patients was small; that is why, the research results, especially of the regression analysis, should be limited. Still, the results are consistent with the findings of other authors. Another limitation is the fact that the data were collected through questionnaires filled out by the patients themselves. The preponderance of subjective judgment of assessment methods, in which we are dependent on the ability of introspection of the patient and his willingness to testify, has its limitations, especially in patients with schizophrenia 
who may have a different degree of cognitive dysfunction. Filling out the questionnaires could also be modified by various levels of fatigue and motivation of the patients. Another limitation is the high number of possible predictors after correlation analysis in a sample size of just 52 patients. To reduce the number of predictors, we separated the predictors into separate regressions of demographic and clinical factors versus personality factors.

Despite these limitations, it seems that self-stigma is a major factor that is associated with certain personality traits and hope of the patient. In the future, it may be useful to examine the effects of self-stigma, personality factors, and hope for a therapeutic outcome in this diagnostic group. The next step would be the development of the particular approaches for changing the factors affecting self-stigma and treatment response and their application in psychoeducation.

\section{Conclusion}

Detection of the quality of life in the context of personality traits, hope, self-stigma and demographic and clinical factors may be an important part of the treatment of patients with schizophrenia. Identifying those life areas in which our patients suffer and finding out those weakened areas of their personality, perception, hope, attitude, and approach toward oneself and others can help in the development of desirable behavior with a positive impact on the overall quality of their life.

We conclude that quality of life in patients suffering from schizophrenia spectrum disorders is influenced by several factors. One of the most important factors seems to be the symptoms severity measured by both global scales (CGI) and scales evaluating the LSAS and depression (BDI-II). We also proved positive correlation with hope and negative correlation with self-stigma. DAI-10 questionnaire also showed a substantial correlation between quality of life and adherence to treatment by drugs. This is quite essential in this patient group. From the range of demographic factors, the presence of occupation superiorly influences the subjective level of quality of life. This result underlines the necessity of job prospect in those with schizophrenia spectrum disorders.

\section{Disclosure}

The authors report no conflicts of interest in this work.

\section{References}

1. Ritsner M, Kurs R, Gibel A, Ratner Y, Endicott J. Validity of an abbreviated quality of life enjoyment and satisfaction questionnaire (Q-LESQ-18) for schizophrenia, schizoaffective, and mood disorder patients. Qual Life Res. 2005;14(7):1693-1703.
2. Browne S, Roe M, Lane A, et al. Quality of life in schizophrenia: relationship to sociodemographic factors, symptomatology, and tardive dyskinesia. Acta Psychiatr Scand. 1996;94(2):118-124.

3. Skantze K, Malm U, Dencker SJ, May PR, Corrigan P. Comparison of the quality of life with standard of living in schizophrenic out-patients. Br J Psychiatry. 1992;161:797-801.

4. Herrman H, Hawthorne G, Thomas R. Quality of life assessment in people living with psychosis. Soc Psychiatry Psychiatr Epidemiol. 2002; 37(11):510-518.

5. Karow A, Naber D. Subjective well-being and quality of life under atypical antipsychotic treatment. Psychopharmacology (Berl). 2002; 162(1):3-10.

6. Wegener S, Redoblado-Hodge MA, Lucas S, Fitzgerald D, Harris A, Brennan J. Relative contributions of psychiatric symptoms and neuropsychological functioning to quality of life in first-episode psychosis. Aust N Z J Psychiatry. 2005;39(6):487-492.

7. Yamauchi K, Aki H, Tomotake M, et al. Predictors of subjective and objective quality of life in outpatients with schizophrenia. Psychiatry Clin Neurosci. 2008;62(4):404-411.

8. Latalova K, Prasko J, Diveky T, Kamaradova D, Velartova H. Quality of life in patients with bipolar disorder - a comparison with schizophrenic patients and healthy controls. Psychiatr Danub. 2011; 23(1):21-26.

9. Wartelsteiner F, Mizuno Y, Frajo-Apor B, et al. Quality of life in stabilized patients with schizophrenia is mainly associated with resilience and self-esteem. Acta Psychiatr Scand. 2016;134(4):360-367.

10. Sidlova M, Prasko J, Jelenova D, et al. The quality of life of patients suffering from schizophrenia - a comparison with healthy controls. Biomed Pap Med Fac Univ Palacky Olomouc Czech Repub. 2011;155(2): 173-180.

11. Holubova M, Prasko J, Hruby R, et al. Coping strategies and quality of life in schizophrenia: cross-sectional study. Neuropsychiatr Dis Treat. 2015;11:3041-3048.

12. Holubova M, Prasko J, Latalova K, et al. Are self-stigma, quality of life, and clinical data interrelated in schizophrenia spectrum patients? A cross-sectional outpatient study. Patient Prefer Adherence. 2016;10: 265-274.

13. Schulze B, Angermeyer MC. Subjective experiences of stigma: a focus group study of schizophrenic patients, their relatives, and mental health professionals. Soc Sci Med. 2003;56(2):299-312.

14. Hasson-Ohayon I, Kravetz S, Meir T, Rozencwaig S. Insight into severe mental illness, hope, and quality of life of persons with schizophrenia and schizoaffective disorders. Psychiatry Res. 2008;167(3):231-238.

15. Gerlinger G, Hauser M, De Hert M, Lacluyse K, Wampers M, Correll CU. Personal stigma in schizophrenia spectrum disorders: a systematic review of prevalence rates, correlates, impact and interventions. World Psychiatry. 2013;12(2):155-164.

16. Wang XQ, Petrini MA, Morisky DE. Predictors of quality of life among Chinese people with schizophrenia. Nurs Health Sci. Epub 2016 Apr 25.

17. Snyder CR, editor. Handbook of Hope: Theory, Measures, \& Applications. New York, NY: Academic Press; 2000.

18. Snyder CR, Rand KL, Sigmon DR. Hope theory: A member of positive psychology family. In: Snyder CR, Lopez SJ, editors. Handbook of Positive Psychology. New York, NY: Oxford University Press; 2002: 257-276.

19. Ocisková M, Sobotková I, Praško J, Mihál V. Standardization of the Czech version of the Snyder's Adult Dispositional Hope Scale. [Standardizace české verze Snyderovy škály naděje pro dospělé. Psychologie a její kontexty. In Czech language]. Psychol Contexts. 2016;7(1): 109-123.

20. Schrank B, Amering M, Hay AG, Weber M, Sibitz I. Insight, positive and negative symptoms, hope, depression, and self-stigma: a comprehensive model of mutual influences in schizophrenia spectrum disorders. Epidemiol Psychiatr Sci. 2014;23(3):271-279.

21. Hanzawa S, Nosaki A, Yatabe K, et al. Study of understanding the internalized stigma of schizophrenia in psychiatric nurses in Japan. Psychiatry Clin Neurosci. 2012;66(2):113-120. 
22. Livingston JD, Boyd JE. Correlates and consequences of internalized stigma for people living with mental illness: a systematic review and meta-analysis. Soc Sci Med. 2010;71(12):2150-2161.

23. Vrbová K, Kamarádová D, Látalová K, et al. Self-stigma and adherence to medication in patients with psychotic disorders - cross-sectional study. Neuro Endocrinol Lett. 2014;35(7):645-652.

24. Yanos PT, Roe D, Lysaker PH. The impact of illness identity on recovery from severe mental illness. Am J Psychiatr Rehabil. 2010; 13(2):73-93.

25. Rüsch N, Corrigan PW, Powell K, et al. A stress-coping model of mental illness stigma: II. Emotional stress responses, coping behavior and outcome. Schizophr Res. 2009;110(1-3):65-71.

26. Margetić BA, Jakovljević M, Ivanec D, Margetić B, Tošić G. Relations of internalized stigma with temperament and character in patients with schizophrenia. Compr Psychiatry. 2010;51(6):603-606.

27. Wahl OF. Mental health consumers' experience of stigma. Schizophr Bull. 1999;25:467-478.

28. Sirey JA, Bruce ML, Alexopoulos GS, et al. Perceived stigma as a predictor of treatment discontinuation in young and older outpatients with depression. Am J Psychiatry. 2001;158(3):479-481.

29. Watson AC, Corrigan PW, Larson JE, Sells M. Self-stigma in people with mental illness. Schizophr Bull. 2007;33(6):1312-1318.

30. Gaebel W, Zäske H, Baumann AE, et al. Evaluation of the German WPA "program against stigma and discrimination because of schizophreniaOpen the Doors": results from representative telephone surveys before and after three years of antistigma interventions. Schizophr Res. 2008; 98(1-3):184-193.

31. Yanos PT, Roe D, Markus K, Lysaker PH. Pathways between internalized stigma and outcomes related to recovery in schizophrenia spectrum disorders. Psychiatr Serv. 2008;59(12):1437-1442.

32. Yen CF, Chen CC, Lee Y, Tang TC, Ko CH, Yen JY. Association between quality of life and self-stigma, insight, and adverse effects of medication in patients with depressive disorders. Depress Anxiety. 2009 26(11):1033103-1033109.

33. Cavelti M, Kvgic S, Beck E, Rüsch NA, Vauth R. Self-stigma and its relationship with insight, demoralization, and clinical outcome among people with schizophrenia spectrum disorders. Compr Psychiatry. 2011; 53(5):468-479.

34. Kamaradova D, Latalova K, Prasko J, et al. Connection between selfstigma, adherence to treatment, and discontinuation of medication. Patient Prefer Adherence. 2016;10:1289-1298.

35. West ML, Yanos PT, Smith SM, Roe D, Lysaker PH. Prevalence of internalized stigma among persons with severe mental illness. Stigma Res Action. 2011;1(1):3-10.

36. Brohan E, Elgie R, Sartorius N, Thornicroft G; GAMIAN-Europe Study Group. Self-stigma, empowerment, and perceived discrimination among people with schizophrenia in 14 European countries: The GAMIAN-Europe study. Schizophr Res. 2010;122(1-3):232-238.

37. Goffman E. Stigma. Notes on the Management of Spoiled Identity. New York, NY: Touchstone; 1986.

38. Gray AJ. Stigma in psychiatry. J R Soc Med. 2002;95:72-76.

39. Hajda M, Kamaradova D, Latalova K, et al. Self-stigma, treatment adherence, and medication discontinuation in patients with bipolar disorders in remission - a cross sectional study. Act Nerv Super Rediviva. 2015;5(1-2):6-11.

40. Barney LJ, Griffiths KM, Jorm AF, Christensen H. Stigma about depression and its impact on help-seeking behavior. Aust $N$ Z J Psychiatry. 2006;40(1):51-54

41. Alonso J, Buron A, Bruffaerts R, et al; World Mental Health Consortium. Association of perceived stigma and mood and anxiety disorders: results from the World Mental Health Surveys. Acta Psychiatr Scand. 2008;118(4):305-314.

42. Camp DL, Finlay WML, Lyons E. Is low self-esteem an inevitable consequence of stigma? An example from women with chronic mental health problems. Soc Sci Med. 2002;55(5):823-834.

43. Cloninger CR. The Temperament and Character Inventory (TCI) A Guide to Its Development and Use. St. Louis, MO: Centre for Psychobiology of Personality; 1994.
44. Farmer RF, Goldberg LR. A psychometric evaluation of the revised Temperament and Character Inventory (TCI-R) and the TCI-140. Psychol Assess. 2008;20(3):281.

45. Sheehan DV, Lecrubier Y, Sheehan KH, et al. The mini-international neuropsychiatric interview (M.I.N.I.): the development and validation of a structured diagnostic psychiatric interview for DSM-IV and ICD-10. J Clin Psychiatry. 1998;59(suppl 20):22-33.

46. Mezinárodní klasifikace nemocí - 10. revize, MKN-10 [International classification of the disorders - 10th revision]. (1. vydání). Praha: Maxdorf; 1996. Czech.

47. American Psychiatric Association. Diagnostic and Statistical Manual of Mental Disorders DSM-5. 5th ed. Arlington: American Psychiatric Association; 2013.

48. Guy W, editor. ECDEU Assessment Manual for Psychopharmacology. Rockville, MD: U.S. DHEW; 1976.

49. Müllerova $H$. Transcultural transmission and validation of the quality life questionnaire Q-LES-Q. [in Czech: Mezikulturní přenos a validace dotazníku kvality života Q-LES-Q]. Psychiatrie. 2001;5:80-87.

50. Liebowitz MR. Social phobia. Mod Trends Pharmacopsychiatri. 1987;22:141-173.

51. Fresco DM, Coles ME, Heimberg RG, et al. The Liebowitz Social Anxiety Scale: a comparison of the psychometric properties of selfreport and clinician-administered formats. Psychol Med. 2001;31(6): 1025-1035.

52. Baker SL, Heinrichs N, Kim HJ, Hofmann SG. The Liebowitz Social Anxiety Scale as a self-report instrument: a preliminary psychometric analysis. Behav Res Ther. 2002;40(6):701-715.

53. Ritsher JB, Otilingam PO, Grajales M. Internalized stigma of mental illness: psychometric properties of a new measure. Psychiatry Res. 2003; 121(1):31-49.

54. Boyd JE, Adler EP, Otilingam PG, Peters T. Internalized Stigma of Mental Illness (ISMI) Scale: a multinational review. Compr Psychiatry. 2014;55(1):221-231.

55. Ocisková M, Praško J, Kamarádová D, et al. Self-stigma in psychiatric patients - standardization of the ISMI scale. Neuro Endocrinol Lett 2014;35(7):624-632.

56. Beck AT, Epstein N, Brown G, Steer RA. An inventory for measuring clinical anxiety: psychometric properties. J Consult Clin Psychol. 1988;56(6):893-897.

57. Kamaradova D, Prasko J, Latalova K, et al. Psychometric properties of the Czech version of the Beck Anxiety Inventory - comparison between diagnostic groups. Neuro Endocrinol Lett. 2015;36(7):706-712.

58. Beck AT, Steer RA, Ball R, Ranieri W. Comparison of Beck Depression Inventories-I and -II in psychiatric outpatients. J Pers Assess. 1996; 67(3):588-597.

59. Domino G, Domino ML. Psychological Testing: An Introduction. Cambridge: Cambridge University Press; 2006.

60. Preiss M, Vacír K. Beckova sebeposuzovací škála depresivity pro dospělé. BDI-II [Beck self-rate scale for depression for adults]. Př́ručka. Brno: Psychodiagnostika; 1999. Czech.

61. Gillespie NA, Cloninger CR, Heath AC, Martin NG. The genetic and environmental relationship between Cloninger's dimensions of temperament and character. Pers Individ Dif. 2003;35:1931-1946.

62. Preiss M, Klose J. Diagnostic of personality disorders using theory of C.R.Cloninger. [Diagnostika poruch osobnosti pomocí teorie C. R. Cloningera. In the Czech language]. Psychiatrie. 2001;5: 226-231.

63. Hogan TP, Awad AG, Eastwood R. A self-report scale predictive of drug compliance in schizophrenics: reliability and discriminative validity. Psychol Med. 1983;13(1):177-183.

64. EMEA. 2002. Available from: http://www.ema.europa.eu/docs/en_GB/ document_library/Scientific_guideline/2009/09/WC500003526.pdf. Accessed August 25, 2016.

65. World Medical Association [webpage on the Internet]. WMA Declaration of Helsinki - Ethical Principles for Medical Research Involving Human Subjects. Ferney-Voltaire, France: WMA; 2013. Available from: http://www.wma.net/en/30publications/. Accessed January 24, 2017. 
66. Češková E, Přikryl R, Pěč O. Schizofrenie u dospělých. In: Raboch J, Uhlíková P, Hellerová P, Anders M, Šusta M, editors. Psychiatry: Guidelines of psychiatric care IV. [Psychiatrie. Doporučené postupy psychiatrické péče IV. In the Czech language]. Prague: Psychiatrická společnost ČSL JEP; 2014:44-51.
67. Cloninger CR. A unified biosocial theory of personality and its role in the development of anxiety states. Psychiatr Dev. 1986;3:167-226.

68. Kose S. A psychobiological model of temperament and character: TCI. Yeni Symp. 2003;41(2):86-97.

\section{Publish your work in this journal}

Neuropsychiatric Disease and Treatment is an international, peerreviewed journal of clinical therapeutics and pharmacology focusing on concise rapid reporting of clinical or pre-clinical studies on a range of neuropsychiatric and neurological disorders. This journal is indexed on PubMed Central, the 'PsycINFO' database and CAS, and is the official journal of The International Neuropsychiatric Association (INA). The manuscript management system is completely online and includes a very quick and fair peer-review system, which is all easy to use. Visit http://www.dovepress.com/testimonials.php to read real quotes from published authors.

Submit your manuscript here: http://www.dovepress.com/neuropsychiatric-disease-and-treatment-journal 